\title{
Treatment of notalgia paresthetica with low dose pregabalin: Retrospective evaluation of 13 patients
}

\author{
Sertaç Şener ${ }^{1}$, Fadime Kılınç ${ }^{2}$, Ayşe Akbaş², Akın Aktaş ${ }^{3}$ \\ ${ }^{1}$ Private Clinic, Dermatology, Ankara, Turkey, ${ }^{2}$ Ankara City Hospital, Dermatology, Ankara, Turkey, ${ }^{3}$ Yildirim Beyazit \\ University Medical Faculty, Dermatology, Ankara, Turkey
}

Corresponding author: Fadime Kılınç, MD, E-mail: fykilinc@yahoo.com

\begin{abstract}
Background: Notalgia paresthetica (NP) is a sensory neuropathic syndrome characterized by chronic itching of the unilateral mid-back. Topical and systemic symptomatic treatments have been used to date. In recent years, neuropathic pain medicine has been used to relieve the symptoms of the disease. The aim of this study was to determine the effectiveness of pregabalin in notalgia paresthetica. Materials and Methods: In this study, the files of the patients with a diagnosis of NP and treated with pregabalin for at least one month in the period between 2016 and 2018 were evaluated retrospectively. Results: Thirteen cases of NP treated with low-dose (up to $150 \mathrm{mg} /$ day) pregabalin were evaluated, and $9(70 \%)$ patients exhibited a good response in this retrospective study. All patients were female and the mean age was $53.5(31-71) \pm 10.3$ years. The mean disease duration was $6.1(1-10) \pm 4.1$ years. Conclusion: Treatment with low-dose pregabalin may be a good option for the symptomatic treatment of NP.
\end{abstract}

Key words: Neuropathic pruritus, Neuropathic pain, notalgia paresthetica, pregabalin

\section{INTRODUCTION}

Notalgia paresthetica (NP) is a sensory neuropathic syndrome with chronic and severe itching (neuropathic pruritus) localized in the mid-back. Clinically, a hyperpigmented patch on the back that is generally unilateral and restricted to a small part of the T2-T6 dermatomal areas is observed [1-3]. NP may also be accompanied by other disturbing sensory symptoms, such as burning pain, paresthesia, dysesthesia, or hyperesthesia. Rarely, hypoesthesia is also noted. Most of the patients are middle-aged and older females [1,2]. Although the etiopathogenesis of the disease is not fully known, genetic predisposition, increased dermal innervation, viscerocutaneous reflex mechanisms, sensorial neuropathy due to neurotoxic agents, and dorsal spinal nerve injury are emphasized [4].

Numerous agents have been used for the treatment of NP. Topical agents, such as capsaicin, corticosteroids, local anesthetic drugs, or botulinum toxin A injections, are typically used. In addition to transcutaneous electrical nerve stimulation, acupuncture, exercise, and surgical decompression have been employed. Antihistamines, amitriptyline, and anti-epileptic drugs, such as oxcarbazepine, have also been used systemically in the treatment of NP [4-6]. It has recently been suggested that gabapentin and pregabalin, which are neuropathic pain relievers, may also be used for the treatment of the disease [7]. The aim of this retrospective, observational study was to evaluate the efficacy of pregabalin in patients with NP.

\section{MATERIALS AND METHODS}

In this study, the files of the patients admitted to our outpatient clinic with a diagnosis of NP and treated with pregabalin for at least one month in the period between 2016 and 2018 were evaluated retrospectively. The patients' responses to any symptomatic treatment were recorded as either none, slight, moderate, good, or

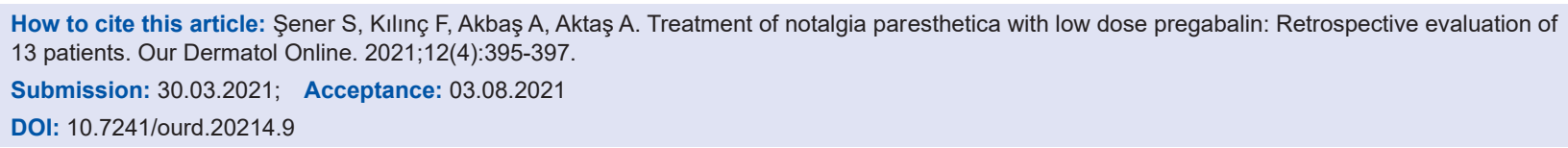


very good in the general daily practice of our outpatient clinic. We used these descriptions in this study.

\section{RESULTS}

Thirteen patients with NP were treated with pregabalin in the period between 2016 and 2018 according to hospital records. Diagnosis was based on clinical findings in ten patients and confirmatory biopsies were performed in three patients. All patients were female and the mean age was $53.5(31-71) \pm 10.3$ years. The mean disease duration was $6.1(1-10) \pm 4$.1 years. The symptoms were located in the mid-back in all patients. The other clinical characteristics and accompanying diseases, as well as the doses of pregabalin and responses, are shown in Table 1.

All of the patients had previously been treated with topical corticosteroids, systemic antihistamines, or anti-inflammatory medicine. According to records, the patients were started on $25 \mathrm{mg}$ of pregabalin twice daily. In one patient, at the end of two weeks, the dose was increased to $50 \mathrm{mg}$ twice daily. In another patient, the dose was increased to $75 \mathrm{mg}$ twice daily after three weeks.

Three of the patients had a very good response to treatment, six patients had a good response, and four had a moderate response. No side effects were recorded in any patient.

\section{DISCUSSION}

Pain and itching sensations are transmitted via peripheral unmyelinated $\mathrm{C}$ nerve fibers to the dorsal horn of the medulla spinalis and, then, to the thalamus and somatosensory cortex via the lateral spinothalamic tract. Microneurography studies have demonstrated that a small group of histaminesensitive $\mathrm{C}$ nerve fibers transmit pruritus. These $\mathrm{C}$ fibers have spontaneous activity in patients with chronic pruritus [8]. The antipruritic effect of gabapentin and pregabalin has been investigated in a mouse model. Gabapentin and pregabalin inhibit hyperexcitable neurons by modulating the $\alpha_{2} \delta$-l subunit of voltage-dependent calcium channels. These inhibit calcium influx and the subsequent release of excitatory neurotransmitters [9].

Numerous receptors and mediators play a role in the transmission of itching. There are similarities and interactions between the neurotransmitters of pain and itching. Gabapentin and pregabalin used for the treatment of neuropathic pain are thought to be applicable to pruritus given this close relationship [9-10]. Maciel et al. reported that the response to treatment of ten patients with NP with $300 \mathrm{mg}$ of gabapentin daily for four weeks was significantly better than the other ten patients with 0.025\% topical capsaicin [7].

Pregabalin is a similar molecule to gabapentin, with some pharmacological advantages such as fast absorption, linear elimination, and fewer side effects. The most common side effects are sedation, dizziness, and drowsiness [10].

Pregabalin has been previously used in various clinical conditions for the treatment of pruritus in dermatology. Atıs et al. reported good results with $100 \mathrm{mg}$ of

POLAND_1940_Treatment

Table 1: Clinical characteristics and treatment responses of the patients

\begin{tabular}{|c|c|c|c|c|c|c|c|}
\hline Patient No. & Age & $\begin{array}{c}\text { Disease } \\
\text { Duration (yrs.) }\end{array}$ & $\begin{array}{l}\text { Mid-back } \\
\text { Symptom Side }\end{array}$ & $\begin{array}{l}\text { Accompanying } \\
\text { Diseases }\end{array}$ & $\begin{array}{l}\text { Neuro/orthopedical } \\
\text { Problems }\end{array}$ & $\begin{array}{c}\text { Pregabalin } \\
\text { Dose (mg/day) }\end{array}$ & Response \\
\hline 1 & 54 & 4 & Right & Hyperlipidemia & Sacroiliitis & $2 \times 25$ & Good \\
\hline 2 & 49 & 10 & Bilateral & Hyperthyroidism & & $2 \times 50$ & Moderate \\
\hline 3 & 46 & 10 & Bilateral & Polycythemia & & $2 \times 25$ & Moderate \\
\hline 4 & 64 & 5 & Right & Diabetes mellitus & Cervical discopathy & $2 \times 25$ & Good \\
\hline 5 & 59 & 2 & Bilateral & Hypertension & & $2 \times 25$ & Very good \\
\hline 6 & 44 & 1 & Right & Hypothyroidism & & $2 \times 25$ & Good \\
\hline 7 & 31 & 4 & Left & & & $2 \times 25$ & Good \\
\hline 8 & 58 & 3 & Right & & Fibromyalgia & $2 \times 25$ & Moderate \\
\hline 9 & 52 & 7 & Right & & & $2 \times 25$ & Very good \\
\hline 10 & 71 & 2 & Right & & Lumbar discopathy & $2 \times 75$ & Moderate \\
\hline 11 & 47 & 15 & Right & & & $2 \times 25$ & Very good \\
\hline 12 & 62 & 6 & Bilateral & Diabetes mellitus & Fibromyalgia & $2 \times 25$ & Good \\
\hline 13 & 59 & 10 & Right & & Ankylosing spondylitis & $2 \times 25$ & Good \\
\hline
\end{tabular}


pregabalin daily in two of three cases with brachioradial pruritus, while a dose of $225 \mathrm{mg}$ was needed in the third patient [11]. In thirty patients with prurigo nodularis, $75 \mathrm{mg}$ of pregabalin daily was used for three months, which provided satisfactory relief in $23(76 \%)$ patients [12].

To the best of our knowledge, this is the first report of the use of pregabalin in NP. The effective dose of pregabalin for neuropathic pain ranges between 150 and $600 \mathrm{mg}$. However, studies indicate that the use of very low doses is sufficient for itching. Although there is no standard dose for the symptomatic treatment of pruritus, it is recommended to begin with a very low dose compared with the treatment of neuropathic pain and adjust the dose and duration of the treatment according to the patient's needs. Thus, side effects are also minimized [13]. In our study, pregabalin provided satisfactory relief at a dose of $25 \mathrm{mg}$ twice a day in eleven out of thirteen patients in four weeks. Two patients required slightly higher doses: $100 \mathrm{mg}$ and $150 \mathrm{mg}$, separately.

Symptomatic treatment of NP is as important as the treatment of the underlying pathology if detected. A good or very good response was obtained in nine $(70 \%)$ out of thirteen patients with symptomatic treatment of NP with low-dose pregabalin in this study.

In conclusion, low-dose pregabalin treatment may be a good option for the symptomatic treatment of NP. The limitations of our study were its retrospective nature and the absence of a control group. The findings of the present study encourage further prospective and controlled studies.

\section{Statement of Human and Animal Rights}

All the procedures followed were in accordance with the ethical standards of the responsible committee on human experimentation (institutional and national) and with the 2008 revision of the Declaration of Helsinki of 1975.

\section{Statement of Informed Consent}

Informed consent for participation in this study was obtained from all patients.

\section{REFERENCES}

1. Stumpf A, Ständer S. Neuropathic itch: Diagnosis and management. Dermatol Ther. 2013;26:104-9.

2. Howard M, Sahhar L, Andrews F, Bergman R, Gin D. Notalgia paresthetica: A review for dermatologists. Int J Dermatol. 2018;57:388-92.

3. Malakar S, Mehta P, Malakar S. Dermoscopy of notalgia paresthetica. Our Dermatol Online. 2019;10:317-8.

4. Subașı V, Așkin Ü. Notalgia Parestetika: Olgu Sunumu. Firat Tip Dergisi. 2012;17:43-5.

5. Šitum M, Kolić M, Franceschi N, Pećina M. Notalgia paresthetıca. Acta Clin Croat. 2018;57:721-5.

6. Yeo B, Tey HL. Effective treatment of notalgia paresthetica with amitriptyline. J Dermatol. 2013;40:505-6.

7. Maciel AA, Cunha PR, Laraia IO, Trevisan F. Efficacy of gabapentin in the improvement of pruritus and quality of life of patients with notalgia paresthetica. An Bras Dermatol. 2014;89:570-5.

8. Ikoma A. Updated neurophysiology of itch. Biol Pharm Bull. 2013;36:1235-40.

9. Tsukumo Y, Matsumoto Y, Miura H, Yano H, Manabe H. Gabapentin and pregabalin inhibit the itch-associated response induced by the repeated application of oxazolone in mice. J Pharmacol Sci. 2011;115:27-35.

10. Matsuda KM, Sharma D, Schonfeld AR, Kwatra SG. Gabapentin and pregabalin for the treatment of chronic pruritus. J Am Acad Dermatol. 2016;75:619-25.

11. Atıs G, Bilir Kaya B. Pregabalin treatment of three cases with brachioradial pruritus. Dermatol Ther. 2017;30.

12. Mazza M, Guerriero G, Marano G, Janiri L, Bria P, Mazza S. Treatment of prurigo nodularis with pregabalin. J Clin Pharm Ther. 2013;38:16-8.

13. Mittal A, Agarwal C, Balai M, Taneja A. Gabapentin and pregabalin in dermatology. Indian J Dermatol Venereol Leprol. 2018;84:634-64.

Copyright by Sertaç Şener, et al. This is an open access article distributed under the terms of the Creative Commons Attribution License, which permits unrestricted use, distribution, and reproduction in any medium, provided the original author and source are credited.

Source of Support: Nil, Conflict of Interest: None declared. 